\title{
Insurance Fraud, Case of Albania
}

\section{Dr. Fatbardha Kadiu}

University Aleksander Moisiu, Department of Public Administration

fatbardhakadiu@yahoo.com

\section{Doi:10.5901/mjss.2015.v6n3s1p21}

\begin{abstract}
This paper studies the reasons why the people try to cheat and fraud on insurance companies in Albania. It is represents an overview from the first time of fraud phenomen started. It is showed by the results of the survey how individuals in Albania behave and how do they percept the insurance companies. The survey is conducted on Albanian citizens in the five largest cities. Insurance fraud is a global criminal phenomen, sometime is a part of the companies themselves, and unfortunately we find that it is the case of Albania also. The study approaches into a flat view, analyzing the insurance fraud such as an integral part of financial crime, sometimes as a part of mafia network, sometime as a factor that, but has made deeper the global criminal crisis and the Albanian crisis.
\end{abstract}

Keywords: Insurance, Fraud, Damages, Crime

\section{Introduction}

First methods on transferring and distributing the risk were practiced by Chinese traders, Babylonians. Babylonians developed a system known as the Code of Hammurabi, which was the first census in 1750s BC that was put into practice for the first time for traders traveling through the Mediterranean Sea, from this period the philosophy and the fraud of insurance was developed.

Insurance companies, in their modern concept came up in Britain in the 17th century; it was found the first case of fraud in a legal treatment. Since then, the story has previously recognized the thousands of people or groups of individuals willing to dare, to cheat, and to win more.

This paper intends to describe the scheme of insurance fraud in Albania. Beginning as an individual occurrence it took place in collective fraud, to the highest point where the companies themselves became part of the economic crime. It will be analyzed not only the phenomenon of interpreting the cheating in numbers but also it will try to clarify the reasons that lead an individual or group of individuals to "fraud".

The topic examines the motives that lead to fraud, insurance swindlers typology, consequences of fraud and ways to prevent it. Unlike other products, insurance are not something that can be tested before you buy. When buying insurance undertakes a promise that will take place in the future, by paing the damages for losses. Promises that come when purchasing insurance appear in the contract or insurance policy which defines the rights and obligations of the parties to the contract.

\section{Overview on Evolution of Insurance Fraud}

Every year, there are thousands of fraud cases reported to insurance companies. It seems as if there is a frenetic race of people willing to do anything, except work, to earn a lot and quickly. Thousands of cases involving fraud as fictitious death, burning of houses, pseudo-auto accidents, are filled annually statistics creating a fund worthy fund.

Insurance fraud occurs when an action is performed in order to obtaining what is not right and does not belong to. False claims of insurance are insured by the insurance company in order to obtain what does not belong to them.

Insurance fraud has always existed since the beginning of the insurance as a commercial enterprise. It has undergone thousands of perfection and today deviations appear with images of rich, powerful and successful people. A few years ago, 28 million Britons were targeted by fraudsters, losing a total of nearly 1 billion dollars. As in previous times, increases in the cost of damages due to fraud have led to higher insurance rate. About $15 \%$ of all claims for damages are subject to fraud, $6 \%$ of all payments go to swindlers. Reducing fraud rate is a key issue today for insurance companies. 
Fraudulent activities also affect the lives of innocent people, both directly through accidental injury or intentional damage and indirectly these crimes cause increased insurance premium. Insurance fraud is a significant problem for governments and other organizations which are making efforts to prevent it and also the idiom "The motive of insurance company is: all insurance crimes are financial gain ${ }^{1}$. Insurance contracts provide as insurers and the insured the right usage and opportunities for fraud.

How is Albania implicated in this fight? Many have cheated beyond imagination. Since Victor Lustig who sold the tower "Eiffel" for iron; famous forger Frank Abagnale ${ }^{2}$ who made history with his forgery; Christopher Rocancourt ${ }^{3}$, orphan abandoned by alcoholic parents, before being posed as Rockefeller family aristocrat; Ferdinand Demaret "changed" 11 characters posing as a monk, surgeon to the editor, to the directors of AIG (American Insurance Group), the list is endless.

This is only one part of the coin; towards economic crime the situation is really shocking. Many deceivers keep a low profile, not wanting to get noticed, but they can not always hide. Since the end of the 19th century, European states and the USA, undertook a very serious initiative to prepare a legal framework that would ensure not only the effective supervision of the insurance market, but above all it legislative package would serve to prevent cases of fraud through fraudulent claims and also possible cases of fraud ledded by the insurance companies.

But in fact no measures could still eliminate the phenomenon of insurance fraud. However it should be noted that the entirety of the measures taken has proved to be really necessary.

\section{Risk of Fraud}

According to all the research and studies of organizations specialized in the Detection and Prevention of Fraud Risk it results an increase in the risk of fraud trends. Interesting is the fact that in periods of economic downturns fraud incidents increases. A specialized institution, VMIA - Managed VITORIAN INSURANCE AUTHORITY with much experience in the insurance market, after much study concludes that insurance fraud is an area that is showing increasing activity 4 .

A UK study conducted by RSA, shows that 1.4 million Britons think that the possibility of involvement in an insurance fraud is more common now than it was 24 months ago ${ }^{5}$, for challenges due to the economic situation. The study showed that 4.7 million Britons do not think that a complaint or a lawsuit fake is wrong and only half of those involved in the study were under the impression that lying was wrong. The study which took place in January 2011, suggests that the economic situation may lead to a lack of public law behavior and can orinet community to securities fraud.

Taking into account, on one side the insurance fraud and in turn, the fact that every company should serve as risk consulting to clients and the state, is also conscious VMIA that to evaluate the risk of fraud requires wider community. The main risk is that fraud is growing in all its forms and therefore commitment to undertake research, examinations, internal controls, audits and external audits should be increased.

On the other hand, CPA Australia, the institution of financial supervision in insurance in Australia, has determined effort by small businesses or medium-sounding in their cash flow while the curves / fall could lead to an increase in exposure to "acts of vandalism". While the global financial crisis is expanding, clutching the Australian economy, there is an increased risk that various individuals or groups involved in fraud while their incomes fall and annual income level also. This can be a good benchmark for our country too.

For more than 10 years, the German Insurance Association - GDV, has conducted a survey through anonymous surveys,in order to identify the motives of fraud. Finally in October 2008, they actualized the data of the study. At the conclusion of this study, it was concluded that the insurance fraud may arise from insured persons, but also the company's staff may be implicated, even the leaders. We have to face the truth: fraudulent behavior is a reflection of a lack of conscience that is doing something wrong. But if it's an insurance company, this behavior shows a lack of respect for the customer. However, the fight against fraud can not function without a strong will, to design better institutional cooperation within an effective legal package.

\footnotetext{
1 Manes, a; "Insurance Crime", Journal of Criminal Law and Crinomlogy, Vol, 35,1. 1944. pg 34

2 Franck Abagnale, "Catch me if you can", 2000.

${ }^{3}$ Chrsitopher Rocancourt, "French Rockefeller", 1997.

4 VMIA; Maneged Vitorian Insurance Authority, Risk Management Report, 2002.

${ }^{5}$ RSA; "Consumer Perception on Secutirty", Report of October 2014
} 


\section{Albanian Insurance Market}

The insurance market was liberalized in 1999 and since that time has been made many changes. Qualitative and quantitative changes resulted in an increased of civil conscience, with greater responsibility towards themselves. Despite major changes, again the market has remained small comparing with neighborhood countries which is 10 times lower in payment per capita payments. On the other hand, the number of insurance companies operating in this market for both areas: life and non-life, has increased significantly: the market currently has 9 insurance companies, which offer different types of insurance. The Albanian insurance market is more focused on vehicle insurance, which is based on the law on compulsory insurance of those assets, which is obligatory in all the world and aims to safeguard the financial interests of users.

Moreover, on the Supervisory Authority report, most of the insurance premiums are mandatory insurance, while in a developed market; voluntary insurance must be greater than the mandatory ones.

These situations demonstrate that even there is a considerable number of companies operating in this market, Albanian citizens still have not given proper place and importance to this industry and the importance it has on people's lives.

The government has a legal obligation to build the necessary basis and laws for the protection of consumers' interests to be transparent and to play a real role as a regulator of the market, to protect the interests of the citizens of secured and unsecured citizens. In a word, it has to conduct legal mission. All events occurring on land and sea, burns, explosions of gas cylinders, floods, accidents, debris and soil significant risks that have undergone villages and buildings in the cities, all sorts of accidents and many other events are financially uncovered. Well, this makes it necessary to develop the culture and insurance legislation. Now let see the types of insurance in the Albanian market for 2013 and 2014 and the damaged paid respectively.

Payments from Premium
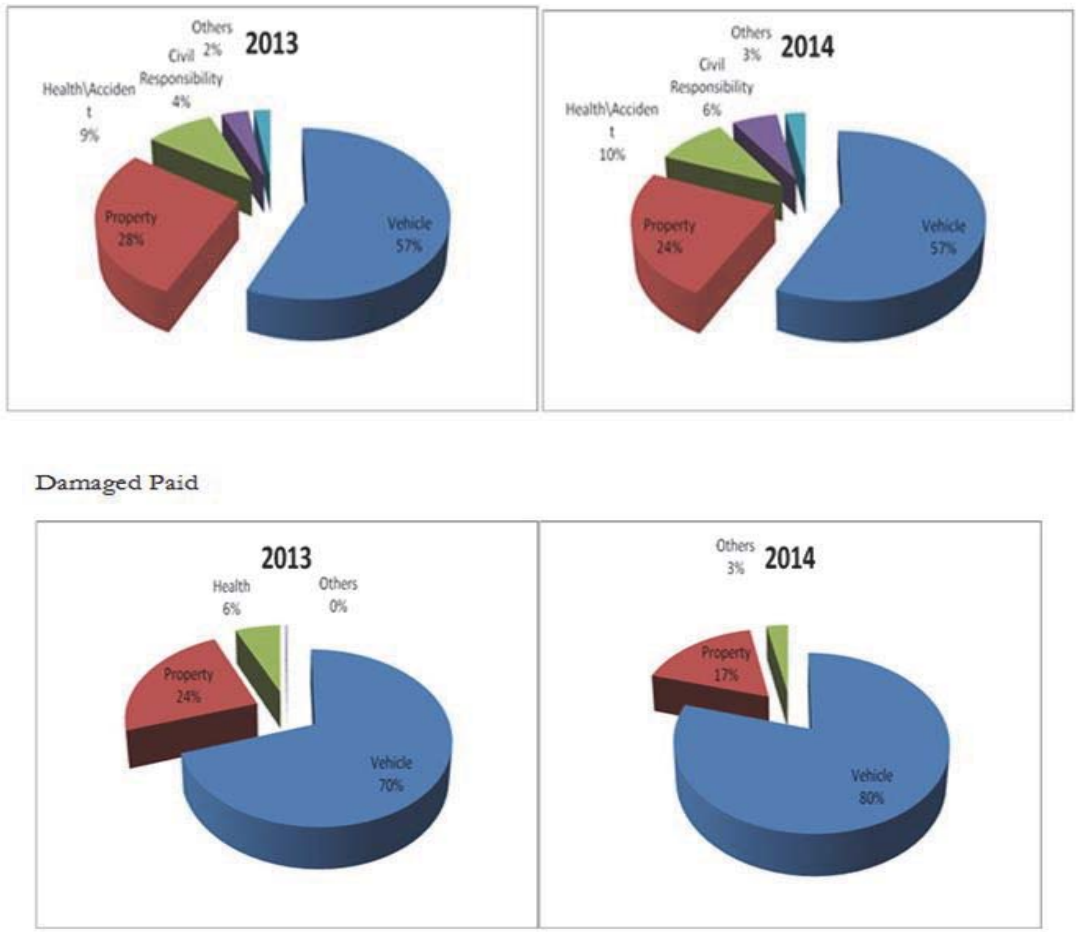

In January-April 2013 the insurance market had a 3.87\% increase. The volume of premiums increased by 103.667 thousand ALL and reached 2,781,111 thousand ALL ${ }^{6}$. Number of contracts represents an increase with 3:38\% compared with January-April 2012.

${ }^{6}$ AMF Albania "Raport Prill 2013" 

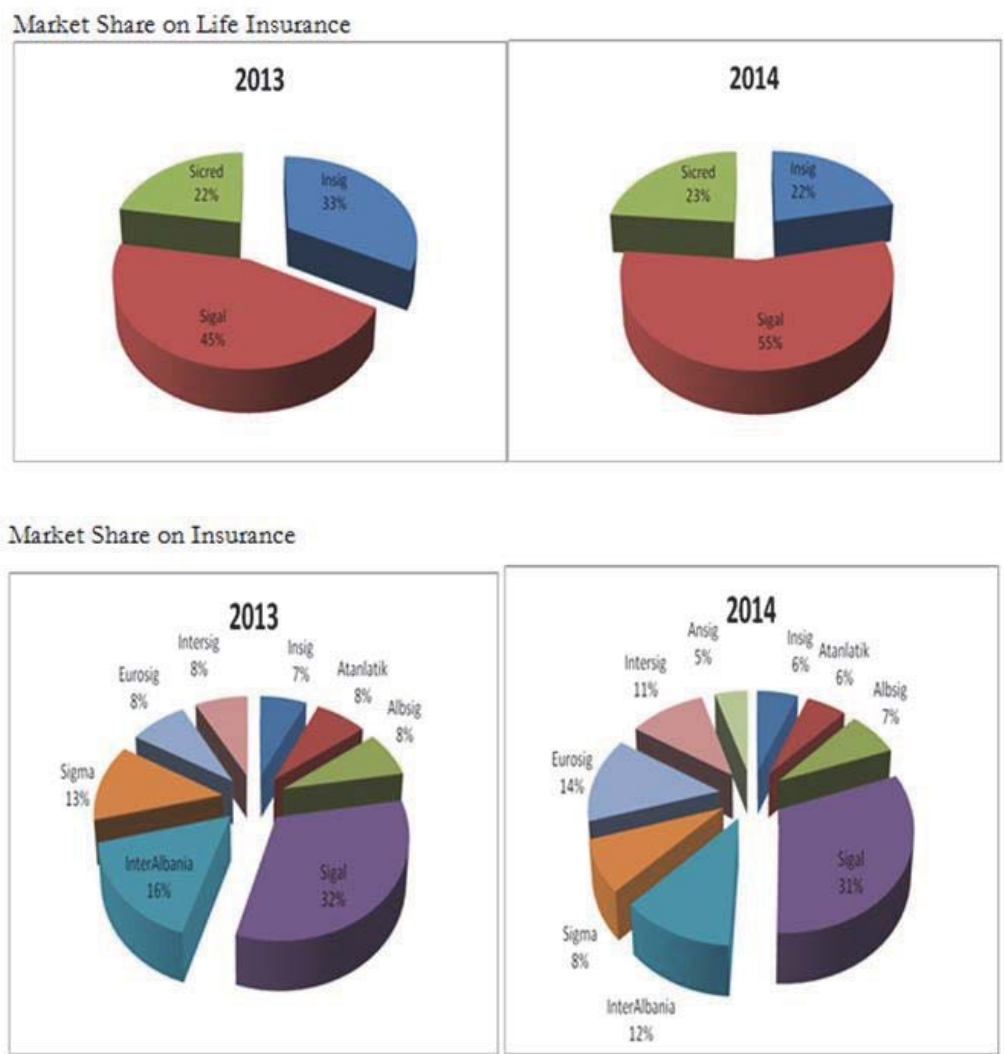

\section{What Would be an Optimal Solution?}

As most of the damaged are paid on accidents from the servey it comes out that most typical accidents are: accidents during the night or in the hours without traffic; in desert areas without witnesses; crash or violation of rights; serious damage to property, etc. There is an optimal solution for everything but the case may have different solutions and in my opinion some of them may be:

- Insurance should be associated with training courses. The company alone can not face the fraud so the colleges in the insurance business should collaborate closly to each other.

- Gathering all the cases in the market, suspicious claims and exchange of information between companies need to be done;

- In addition, one can also find other allies in close cooperation with regional and national police authority

- Changing attitudes towards justice and make it work effectively useful without replaceable by any other body.

- Justice needs and financial support to the most modern technical tools for the detection and documentation of evidence etc.

Survey:

1. How many times have you cheated for your insurance the insurance company?

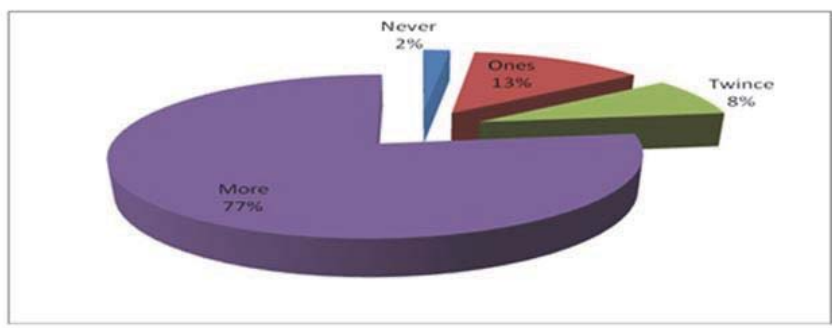

2. If you lose the baggage anf the insurance company will pay just the amount discount from 100 thousand ALL. What will you do? 


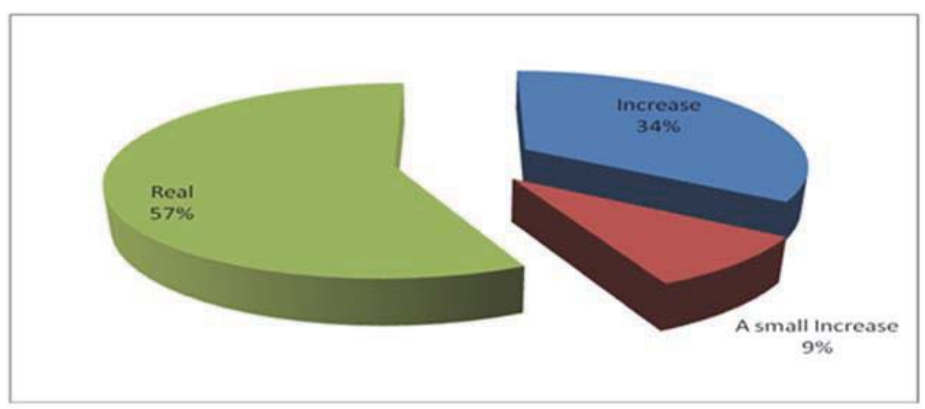

3. Last time that you cheated on the company what kind of insurance was it for?

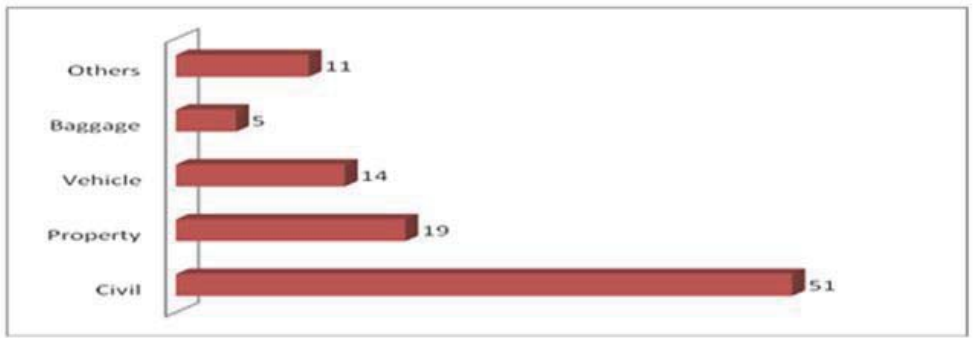

4. Did they undestand your behavior?

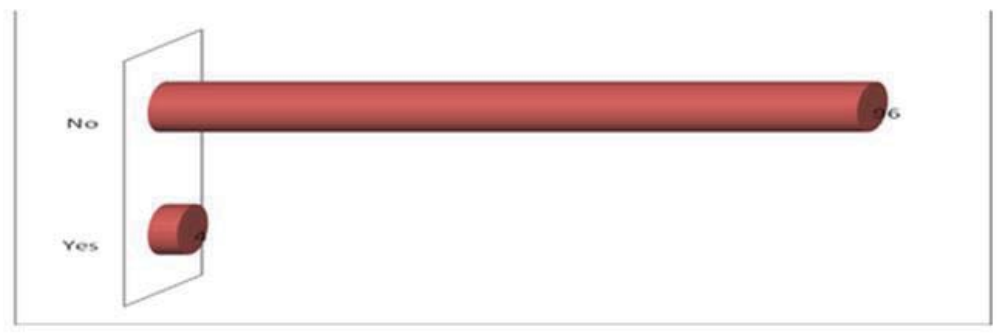

5. Did the employer knew it nad tolerate it in silence?

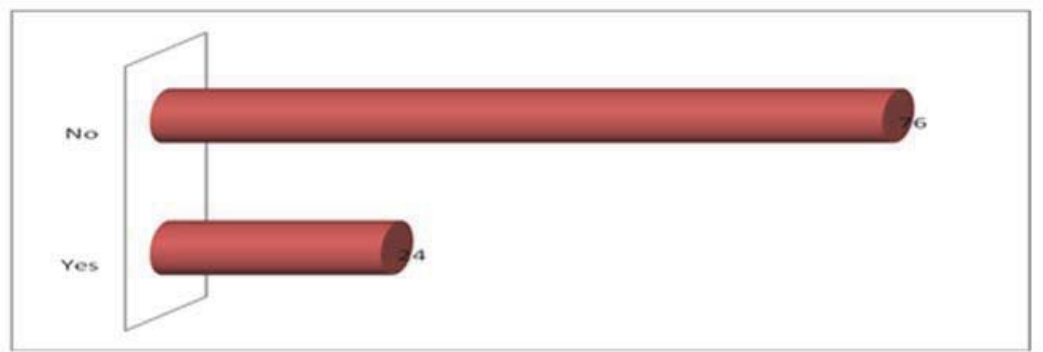

6. Did he support you in an active way? 


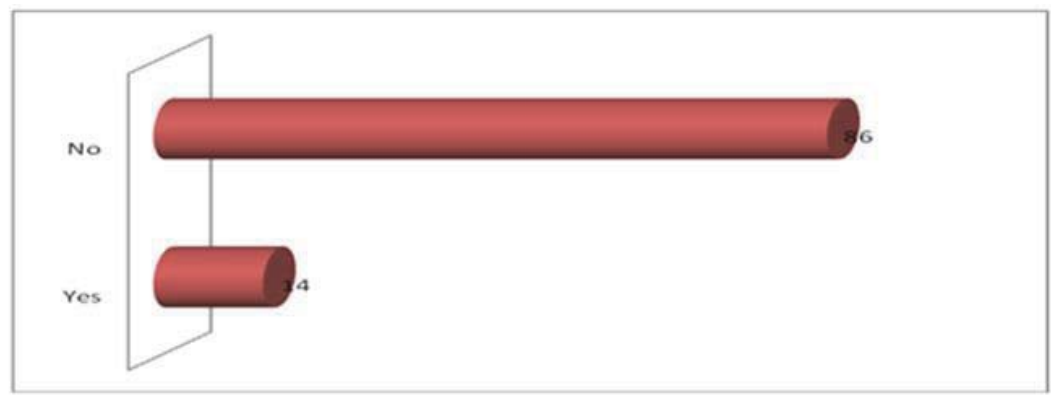

7. Last time that you pretended the damage to be paid by the company how did it llok like?

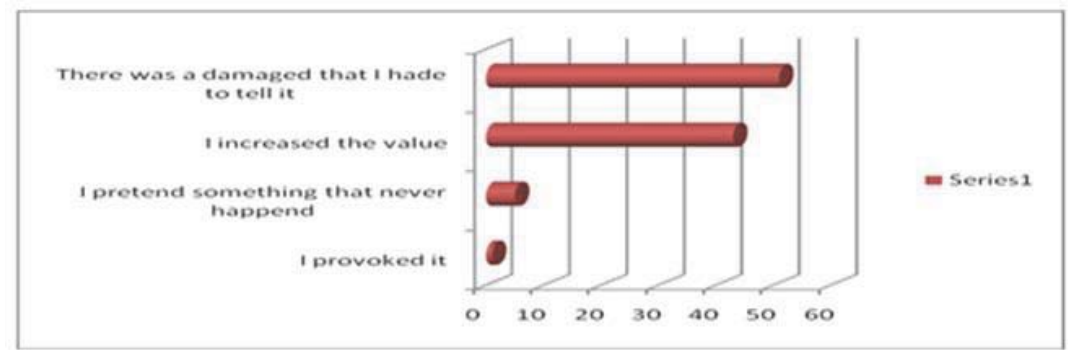

8. If your insurance company is having a lot of earning I feel good:

$>$ I don't agree $44 \%$

$>$ Undecided $17 \%$

I agree $39 \%$

9. Do you think that Insurane Company should not have high profits?

$>$ I don't agree $47 \%$

Undecided $13 \%$

$>$ I agree $40 \%$

10. Companies look forward to collect the premiums and they always delay the payment:

$>$ I don't agree $26 \%$

$>$ Undecided $17 \%$

$>$ I agree $57 \%$

\section{References}

AMF Albania Raport Prill 2013.

Law No. 2967 "Insurance", 1999.

Bank of Albania; Report on Financial Situation on Insurance Companies, 2005.

Manes, a; "Insurance Crime", Journal of Criminal Law, Vol, 35. 1944.

VMIA; Maneged Vitorian Insurance Authority, Risk management report, 2002.

RSA; "Consumer Perception on Security", Report of October 2014. 